\title{
IoTs Hydroponics System: Effect of light condition towards plant growth
}

\author{
Mohammad Zulfikre Esa ${ }^{1}$, Muhammad Saifullah Abu Bakar ${ }^{2}$, Pg Emeroylariffion Pg \\ Abas $^{3}$, Liyanage C De Silva ${ }^{4}$, Faizah Metali ${ }^{5}$ \\ \{icky.fikre@gmail.com¹, saifullah.bakar@ubd.edu.bn ${ }^{2}$, emeroylariffion.abas@ubd.edu.bn ${ }^{3}$ \} \\ Faculty of Integrated Technologies, Universiti Brunei Darussalam, Jalan Tungku Link, BE1410, \\ Brunei Darussalam ${ }^{1}$, Environmental and Life Sciences Programme, Faculty of Science, Universiti Brunei \\ Darussalam, Jalan Tungku Link, Gadong, BE1410, Brunei Darussalam²
}

\begin{abstract}
A hydroponics system with the integration of various sensors has been assembled suitable for small space area such as in high-rise buildings. Effect of different light intensity towards the plant growth has been analysed showing almost a two-fold increase with Light Emitting Diode (LED) light, as compared to the natural lighting towards the leaf count, plant height and leaf dry-matter content. Electrical Conductivity (EC) of the nutrients has been shown to be stable within the optimum range for lettuce throughout the experiments. A pH measurement and control system has been succesfully tested and established. It can be concluded that the automated system is suitable for IoT and these data can be integrated onto a developed server for user to obtain data at ease.
\end{abstract}

Keywords: hydroponics, light, ph, electrical conductivity, plant growth, arduino.

\section{Introduction}

Vertical Farming is an agricultural strategy of growing produce in vertically stacked layer within protected environments using currently available farming technologies such as traditional soil system, hydroponics system and aeroponics system. [1]. Advantages of vertical farming include the use of minimal or zero soil, space and energy savings, and the ability to multiply crop yield as compared to traditional land farming. One of the farming technologies that may be adopted in vertical farming is hydroponic system. Essentially, hydroponics is a soil-less farming technique using liquid nutrient solution where roots of the plant is submerged into the solution or grown into an artificial medium. It can be utilised for commercial or residential purposes [1][2]; particularly adopted where growing space and land area are limited, such as planting in high-rise buildings [3]. Different crops may be grown using hyrdoponic system; including herbs, leafy vegetables such as lettuce and kale, and cherry tomatoes. Important parameters in a hydroponic system are total salt concentration, $\mathrm{pH}$ (alkalinity or acidity), and nutrient concentration ratio [4]; to ensure optimal growth of the plant. Better and efficient use of nutrient solution is needed to ensure the correct amount of nutrient level for different plants and hence, ensure optimal plant growth with minimal cost [5]. Other important parameters that needs to be measured and controlled are Electical Conductivity (EC), temperature, humidity and light. Table 1 shows optimum range of $\mathrm{EC}$ and $\mathrm{pH}$ for selected crops. For indoor farming, it is necessary to provide artificial lighting for the plant and farmers have used Light Emitting Diode

ICCSET 2018, October 25-26, Kudus, Indonesia

Copyright $@ 2018$ EAI

DOI 10.4108/eai.24-10-2018.2280609 
(LED) for their gardens; controlling light to optimise plant growth whilst at the same time, helps to reduce energy consumption cost by as much as $15 \%$ [6][7].

Table 1. Optimum range of EC and $\mathrm{pH}$ for selected crops. [4]

\begin{tabular}{lccc}
\hline \multicolumn{1}{c}{ Crops } & EC (ppm) & EC $(\mathrm{mS} / \mathrm{cm})$ & $\mathrm{pH}$ \\
\hline Basil & 500 to 800 & 1.0 to 1.6 & 5.5 to 6.0 \\
Broccoli & 1400 to 1750 & 2.8 to 3.5 & 6.0 to 6.8 \\
Lettuce & 600 to 900 & 1.2 to 1.8 & 6.0 to 7.0 \\
Pak Choi & 750 to 1000 & 1.5 to 2.0 & 7.0 \\
Spinach & 900 to 1150 & 1.8 to 2.3 & 6.0 to 7.0 \\
Strawberry & 900 to 1100 & 1.8 to 2.2 & 6.0 \\
Tomato & 1000 to 2000 & 2.0 to 4.0 & 6.0 to 6.5 \\
\hline
\end{tabular}

In an automated hydroponics system, nutrient is frequently monitored and controlled within the system to ensure important parameters of the system are well maintained and optimised for the particular plant; via the use of multiple sensors, actuators and processors. Extending the concept even further, the agricultural system may be connected to the Internet; allowing it to exchange data and thereby, creating opportunities for integration to the physical world in order to improve its efficiency. Indeed, the concept of Internet of Things (IoTs) in agriculture is not something new and has been demonstrated by various researchers [8]-[13]. Prathibha et. al. have designed a smart agriculture system which is able to remotely monitor temperature and humidity of air in the field. The system also has the ability to send pictures through MMS to farmers should the two parameters diverge from their optimal ranges [8]. In order to modernize agricultural system, Gondchawar and Kawitkar [9] have proposed the use of smart GPS based remote controlled robots to perform tasks such as weeding, spraying, moisture sensing, bird and animal scaring. Smart irrigation and smart warehouse management systems are also included in their proposals. These operations may be controlled through any remote smart device connected to Internet; with different interfacing sensors and camera providing input, Wi-Fi or Zig-Bee modules providing connectivity, multiple actuators providing output and micro-controller such as raspberry pi and Arduino, providing the control mechanism.

Specifically for hydroponics system, various researchers have demonstrated the use of IoTs to monitor and control conditions; such that optimal conditions are maintained to promote optimal growth. The monitoring and control of humidity, temperature, water level and light intensity are demonstrated in reference [10] whilst the control of nutrients in the hydroponics solutions is shown in reference [11]. Palande et al. demonstrate a fully automated hydroponic system (Titan Smartponics) for indoor plant growth that is low cost and easy to operate; utilising off-the-shelf micro-processors such as Arduino and Raspberry Pi, open source software, and a few sensors [12]. An IoT architecture emphasizing the control of water quality in distributed soil-less food production systems adhering to the Industry 4.0 standards is suggested by De Silva [13]. Among the advantages of these proposed systems include control over aspects of plant growth, the ability to customize parameters for a variety of plants and removing reliance on outside atmosphere or environment for plant growth.

Management and analysis of IoT data may also be used to automate processes, predict situations and improve many real-time activities [14]; by combining real-time data and data analytical capabilities. It is important to manage and understand these data towards achieving the intended output, such as the optimisation to increase the yield of produce or managing 
related equipments towards potential efficient usage or energy-saving measures. In this paper, an IoT hydroponics system is designed and fabricated with emphasis on the effects of two different light conditions on the plant growth, and the automation for the $\mathrm{pH}$ measurement and control system. Other parameters are also monitored to ensure consistency with optimum conditions for the plant growth.

\section{Materials and Method Used}

\subsection{The designed hydroponics system}

The main hydroponic system consists of two parallel tubes; housing five pots each and occupying an area of around $0.48 \mathrm{~m}^{2}$. Weir in the tubes is designed to ensure that the roots of the plant is always submerged in water. Hydroponic tank with a capacity of 20 litres, houses a water pump which is capable of pumping liquid nutrients upwards onto the tubes and back onto the tank via gravity. The tank is connected to a main water supply via a float valve system, to ensure constant water level within the tank; to counter the effect of water evaporation from disrupting other parameters such as $\mathrm{pH}$ and EC values. Figure 1 shows the designed hydroponics system.
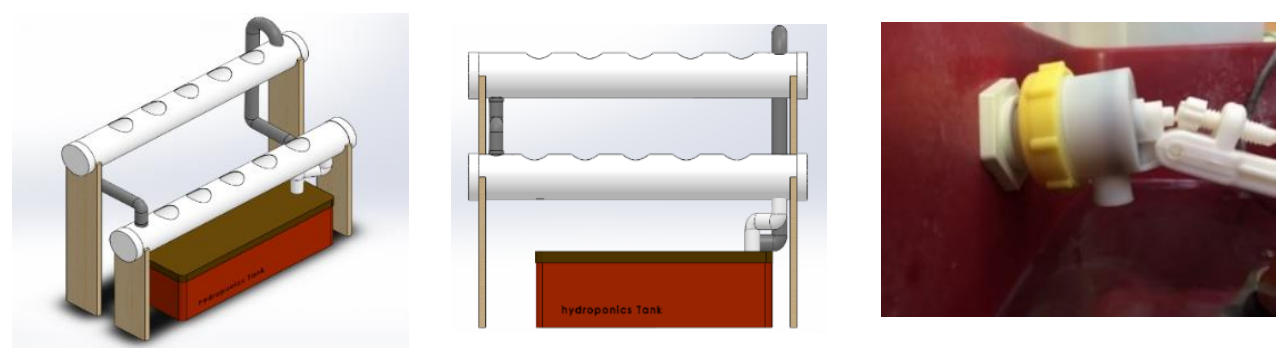

Fig. 1. Hydroponic system illustration - isometric and front view. Float valve system attached to the water mains to ensure constant volume in the tank.

\subsection{Growth environment}

Crop and Nutrients. For this purpose, the plant grown is from lettuce seeds obtained from a local store. Germination of the plants is done separately in a tray with similar conditions. Leafgrow hydroponics nutrient concentrate; containing two solutions A and B, is used in this paper, sourced from a local company specialising in hydroponics equipment and supplies. The solution is first diluted with normal tap water and then, its $\mathrm{pH}$ and EC are determined to within specified ranges suitable for the lettuce. A pH meter and an EC/TDS manual meter are used for these purpose.

Physical Environment. The temperature and the humidity are kept constant throughout, and are easily achievable due to the system being indoors. Two different lighting conditions are considered; with natural lighting and with LED lighting. Light intensity throughout the experiments are recorded. 


\subsection{Automated IoT system}

Program command for this board is written in $\mathrm{C} / \mathrm{C}++$ language through the Arduino compiler/IDE, and is then compiled and uploaded onto the board for the different components to function. Components that are used include a $\mathrm{pH}$ probe with $\mathrm{pH}$ breakout board, Temperature and humidity sensor (DHT11), Real time clock module (DS3231), Light dependent resistor (LDR), Peristaltic DC motor and an ESP-01 Wi-Fi wireless module. The block diagram of the hydroponic system is shown in Figure 2. A 5V port are used to power up electrical devices and components. Components such as $\mathrm{pH}$ circuit, LDRs and DHT11 require initial setup/calibration.

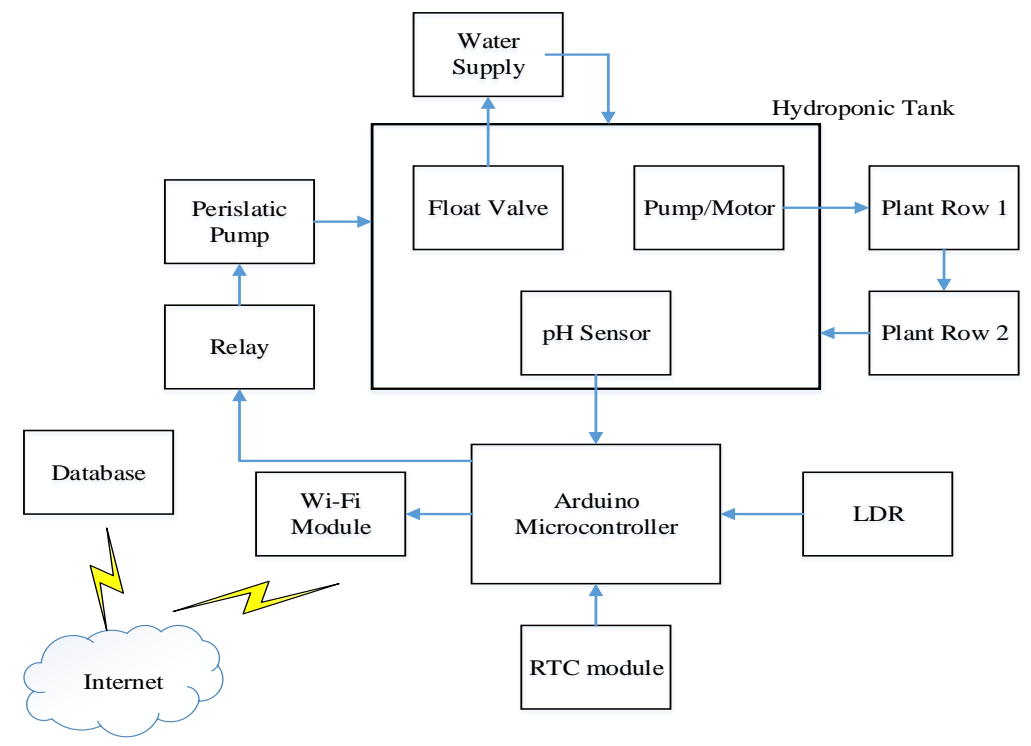

Fig. 2. Block diagram of the hydroponic system.

$\mathrm{pH}$ probe and calibration. The $\mathrm{pH}$ probe is calibrated using three different $\mathrm{pH}$ standard solutions of $\mathrm{pH}$ values 4,7 and 9.2 to give output voltage values of $3.015 \mathrm{~V}, 2.53 \mathrm{~V}$ and $2.16 \mathrm{~V}$ respectively. Line and equation of best fit is then taken and used to map output voltage reading of the $\mathrm{pH}$ probe to its corresponding $\mathrm{pH}$ value; to allow continuous $\mathrm{pH}$ reading of the hydroponic solution.

LDR sensor and calibration. LDR is used to measure light intensity during the experiments. A digital lux meter is used to measure the surrounding light, which is then used to calibrate against the LDR sensor; by comparing the lux of the digital lux meter together with the LDR sensor signal output. Six different light intensities were used to calibrate the LDR, using approximate line of best fit to map output voltage reading of the LDR to its corresponding light intensity.

Temperature and humidity sensors, and calibration. Surrounding temperature and humidity are measured simultaneously using DHT11. Simple thermometer and hygrometer are used to 
calibrate the DHT11; using approximate line of best fit to map output voltage readings of the DHT11 to its corresponding temperature and humidity values. RTC module is used to maintain consistent time and date of the data. It is necessary to install the battery for memory purposes, and the Arduino microcontroller is used to setup time and dates. RTC, pH probe, LDR, temperature and humidity sensor form the sensors of the hydroponic system. Data from the sensors are communicated to a local server via the ESP-01 Wi-Fi wireless module; in order to $\log$ the data. At the same time, data from the $\mathrm{pH}$ probe shall be used to control the Peristaltic DC motor; forming the actuator part of the system. The peristaltic DC motor controls the amount of diluted solutions added to the nutrient solutions; ensuring almost constant $\mathrm{pH}$ value. These operations are controlled by the Arduino microprocessor. The float valve is used to mechanically maintain constant level of water in the hydroponic tank, with the water pump assisting in the circulation of nutrients around the system.

\section{Results and Discussion}

\section{1 pH measurement and control system}

The $\mathrm{pH}$ control system is aimed for growing lettuce, which is ideal between a $\mathrm{pH}$ value of 6 and 7. The trend of the $\mathrm{pH}$ values shows that the value decreases with time. To keep it to an optimal range, sodium bicarbonate $\left(1\right.$ mole $\left.\mathrm{NaHCO}_{3}\right)$ was diluted into nutrient water and $\mathrm{pH}$ changes was recorded. Sodium bicarbonate solution is used due to the alkalinity of the solution being able to increase the $\mathrm{pH}$ and suitability towards plants [15]. Three different measurements were tested using $1 \mathrm{ml}, 0.5 \mathrm{ml}$ and $0.25 \mathrm{ml}$ of $\mathrm{NaHCO} 3$ into 1 litre of the nutrient water. This is required to determine the pumping time. A $12 \mathrm{~V}$ peristaltic pump installed is tested and pumping at rate of $1 \mathrm{ml} / \mathrm{sec}$. The pumping time for the hydroponics system can be determined from the $\mathrm{pH}$ change from the step above, and the corrective delay pump time is determined using the difference in value of $\mathrm{pH}$ at optimum range.

Table 2. $\mathrm{pH}$ control test for 1 litre hydroponics nutrient solution.

\begin{tabular}{ccccc}
\hline \multirow{2}{*}{$1 \mathrm{~mol} \mathrm{NaHCO}$} \\
& \multicolumn{4}{c}{ 1 litre of hydroponics nutrient water } \\
\cline { 2 - 5 } & Initial pH & Final $\mathrm{pH}$ & $\mathrm{pH}$ Difference & \% increase \\
\hline 1.00 & 5.89 & 7.92 & 2.03 & 34.47 \\
0.50 & 5.89 & 6.94 & 1.05 & 17.83 \\
0.25 & 5.87 & 6.42 & 0.55 & 9.37 \\
\hline
\end{tabular}




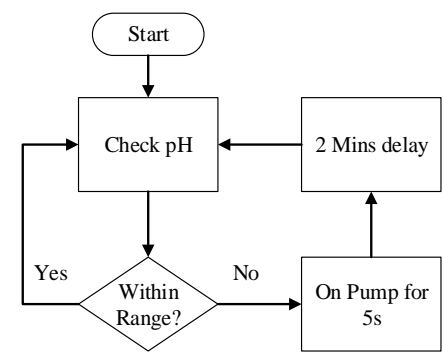

Fig. 3. Flowchart of the $\mathrm{pH}$ control pumping sequence.

Table 2 shows the result from a pH control test for 1 litre nutrient solution in the hydroponics system. From the test above we assume that the changes can be implemented linearly to the 20 litre system. The system will start pumping the sodium bicarbonate once the $\mathrm{pH}$ is out of range. In this case when the $\mathrm{pH}$ starts to fall below $\mathrm{pH} 6$, the aim is to increase to at least a $\mathrm{pH}$ of 6.5 . Since 1 litre of hydroponics nutrient water require 0.55 increments of $\mathrm{pH}$ change, for a 20 litre system, $5 \mathrm{ml}$ of sodium bicarbonate is required. Therefore the pump is set to a 5 second pump time. Figure 3 shows how the automated control system works in controlling the $\mathrm{pH}$ and pumping sequence. In comparison with this work, an advanced hydroponics system by Domingoes et. al has successfully controlled $\mathrm{pH}$ and EC towards lettuce growth [16].

\subsection{Effect of light intensity towards the plants}

A comparison of natural lighting and LED light was done for the hydroponics system. The LED light produces about $960-1080$ Lumens, with input voltage of $5 \mathrm{~V}$ and current of $1.4 \mathrm{~A}$. The LED is placed about $0.3 \mathrm{~m}$ above the second tube. Analysis of the effect of light intensity towards the plant follows some procedures from the handbook by Pérez-Harguindeguy et. al. [17]. Table 3 shows the results from the analyses of plant health towards different lighting conditions. The leaf count and plant height measurement was conducted once every 10 days to calculate the percentage of growth. The leaf dry-matter content was determined when the plants were at Day 30.

Table 3. Analyses of plant leaf count, height and dry matter content for different lighting conditions.

\begin{tabular}{|c|c|c|c|c|c|c|}
\hline & \multicolumn{3}{|c|}{ With natural lighting } & \multicolumn{3}{|c|}{ With LED lighting } \\
\hline Days & $\begin{array}{l}\text { Leaf } \\
\text { count }\end{array}$ & $\begin{array}{c}\text { Average } \\
\text { height }(\mathrm{cm})\end{array}$ & $\begin{array}{c}\text { Average } \\
\text { dry matter } \\
\text { content }(\mathrm{g})\end{array}$ & $\begin{array}{l}\text { Leaf } \\
\text { count }\end{array}$ & $\begin{array}{c}\text { Average } \\
\text { height }(\mathrm{cm})\end{array}$ & $\begin{array}{c}\text { Average } \\
\text { dry matter } \\
\text { content }(\mathrm{g})\end{array}$ \\
\hline Day 10 & 2 & 2.00 & $9 \times 10$ & 2 & 2.40 & \\
\hline Day 20 & $2-4$ & 6.40 & $\begin{array}{l}.59 \times 10 \\
+0.002\end{array}$ & $2-5$ & 7.90 & $\begin{array}{l}.75 \times 10 \\
+0005\end{array}$ \\
\hline Day 30 & $4-5$ & 11.00 & & $4-7$ & 13.94 & \\
\hline
\end{tabular}

This study shows that the leaf count, average height and the average dry matter content values increases about two-fold with LED lighting as compared to natural lighting. This is in agreement with a study done by Zervoudakis et. al which concluded that the plant dry mass and the number of leaves were the highest at full ambient light as compared to shaded lighting areas [18]. 


\section{Conclusion and Future Work}

A hydroponics system with the integration of $\mathrm{pH}$ sensors has been assembled suitable for a small space area such as for high-rise buildings. Effect of different light intensity towards the plant growth has been analysed showing almost a two-fold increase with LED light, as compared to the natural lighting towards the leaf count, plant height and leaf dry-matter content. The EC of the nutrients has been shown to be stable within the optimum range for lettuce throughout the experiments. A pH measurement and control system has been succesfully tested and established. It can be concluded that the automated system is suitable for IoT and these data can be integrated onto a developed server for user to obtain data at ease. Future work include testing the automated $\mathrm{pH}$ measurement and control system towards the plant health to obtain the optimum yield.

\section{Acknowledgments}

The first author would like to acknowledge the Brunei Government Scholarship awarded during this study.

\section{References}

[1] C. Lu and S. Grundy, "Urban Agriculture and Vertical Farming," in Encyclopedia of Sustainable Technologies, 2017.

[2] M. Al-Chalabi, "Vertical farming: Skyscraper sustainability?," Sustain. Cities Soc., vol. 18, pp. 74-77, 2015.

[3] B. Walsh, "Vertical Farming," Time, vol. 172, no. 2, pp. 67-67, 2008.

[4] A. Shrestha and B. Dunn, "HLA-6442 Hydroponic; Oklahoma Cooperative Extension Service," 2017. .

[5] S. W. Van Ginkel, T. Igou, and Y. Chen, "Energy, water and nutrient impacts of California-grown vegetables compared to controlled environmental agriculture systems in Atlanta, GA," Resour. Conserv. Recycl., vol. 122, pp. 319-325, 2017.

[6] M. Mugundhan, M. Soundaria., V. Maheswari., P. Santhakumari., And V. Gopal., “"Hydroponics' A Novel Alternative For Geoponic Cultivation Of Medicinal Plants And Food Crops," Int. J. Pharma Bio Sci., vol. 2, no. 2, p. 11, 2011

[7] J. Birkby, "Vertical Farming," ATTRA Sustainalbe Agriculture. 2016.

[8] S. R. Prathibha, A. Hongal, and M. P. Jyothi, "IOT Based Monitoring System in Smart Agriculture," in 2017 International Conference on Recent Advances in Electronics and Communication Technology (ICRAECT), 2017.

[9] N. Gondchawar and R. S. Kawitkar, "IoT based Smart Agriculture," Int. J. Adv. Res. Comput. Commun. Eng., 2016.

[10] Ms.S.Charumathi, Ms.R.M.Kaviya, and Ms.J.Kumariyarasi, "Optimization and Control of Hydroponics Agriculture Using IoT,” Int. J. Adv. Sci. Eng. Res., 2017.

[11] P. Sihombing, N. A. Karina, J. T. Tarigan, and M. I. Syarif, "Automated hydroponics nutrition plants systems using arduino uno microcontroller based on android," in Journal of Physics: Conference Series, 2018.

[12] V. Palande, A. Zaheer, and K. George, "Fully Automated Hydroponic System for Indoor Plant Growth," in Procedia Computer Science, 2018.

[13] P. C. P. A. De Silva and P. C. P. A. De Silva, "Ipanera: An Industry 4.0 based Architecture for Distributed Soil-less Food Production Systems," Proc. 2016 Manuf. Ind. Eng. Symp. Innov. Appl. Ind., 2016.

[14] A. Tzounis, N. Katsoulas, T. Bartzanas, and C. Kittas, "Internet of Things in agriculture, recent 
advances and future challenges," Biosystems Engineering. 2017.

[15] B. L. Grant, "Sodium Bicarbonate In Gardens: Using Baking Soda On Plants," Gardening know how, 2018. .

[16] D. S. Domingues, H. W. Takahashi, C. A. P. Camara, and S. L. Nixdorf, “Automated system developed to control $\mathrm{pH}$ and concentration of nutrient solution evaluated in hydroponic lettuce production," Comput. Electron. Agric., 2012.

[17] N. Pérez-Harguindeguy et al., "New handbook for standardised measurement of plant functional traits worldwide," Aust. J. Bot., 2013.

[18] G. Zervoudakis, G. Salahas, G. Kaspiris, and E. Konstantopoulou, "Influence of light intensity on growth and physiological characteristics of common sage (Salvia officinalis L.)," Brazilian Arch. Biol. Technol., 2012. 